\title{
Fostering Engineering Students Engagement Using Problem-Based Learning and Course Learner Agent Object Portfolios
}

\author{
https://doi.org/10.3991/ijep.v6i4.6086 \\ Akram Abu-aisheh, Lynroy Grant, Narendar Sumukadas, and Alan Hadad \\ University of Hartford, West Harford, CT, USA
}

\begin{abstract}
Engineering education today is undergoing unprecedented array of challenges including maintaining student engagement during the lecture and throughout the semester. Fostering engineering student engagement in the class room has become a challenging task for engineering educators. In this paper, the authors propose the use of Problem-Based Learning (PBL) to maintain student engagement throughout each lecture and the use of course Learner Agent Object (LAO) portfolio to maintain student engagement in the course throughout the semester.
\end{abstract}

Key Words-Problem-based Learning (PBL), Engineering Student Engagement, and Learner Agent Object (LAO).

\section{INTRODUCTION}

Technology has engendered many successful advances in engineering education, and higher education in general, but also has created urgency for new interdisciplinary arrangements, and tools, for sustaining the mobility a digital teaching and learning environment affords. For example it is still a cumbersome, expensive and opaque process for individuals to navigate issues of economics, of competing interests, of autonomy and of different stakeholders in engineering education infrastructure.

The search for more seamless collaborations is not unique to engineering education. For example, economics is a significant source of interdisciplinary knowledge for the other social sciences and business, but such knowledge is approached with suspicion when no area of economics appears to build substantially on insights from its sister disciplines [1]. There are many research efforts to capitalize new technological advances toward improving seamless interdisciplinary collaborations. One example, from among many, is to explore alternative teaching and learning environments and ecosystems in which the National Science Foundation (NSF) and the journal Science created the International Science and Engineering Visualization competition as a way of promoting alternative forms of communicating science, engineering and technology for education and journalistic purposes, [2-3].

Another example is the collaboration of many institutions to explore opportunities of Open Courseware. However, these partnerships have been generally reactive, piecemeal, and have not resulted in major systemic change for a seamless movement of individuals within K-16 engineering education infrastructure and beyond to lifelong learning as informed citizens.
The purpose of this pilot study is to explore a proof of concept how to capitalize on available technology for creating a more comprehensive and seamless environment which links academic experiences of students from selected CETA classes: between formal settings and non-formal learning, and also between classroom experiences and the workplace.

This study is based on the assumption that cumulative artifacts, simulations, and metadata can represent and influence an individual's learning experiences both in and out of the formal engineering education setting. The study has used Blackboard as container for students' best versions of class assignments called Learner Agent Objects (LAO) individual portfolios. Frequency of access to these documents was used as indicator of student interest, and content of data files were reviewed to measure level of student collaboration. Preliminary results indicated that LAO individual portfolios increased time-on-task and increased emotional investment in quality of class assignments.

The study has raised important questions that require more conversations and research. For example more work is needed to study Personal Digital Containers of Cumulative Knowledge (PDCoCK) system which cultivates cumulative artifacts, simulations, and metadata representing and influencing an individual's learning experiences both in and out of formal K-16 engineering education setting. This limited work only highlight the possibility that LAO could be a useful tool for accommodating transparent collaboration between the different academic traditions in STEM education as technology continues to enabling unprecedented changes in our lives.

\section{LEARNER MOBILITY}

The Literature shows strong relationship between timeon-task and positive learning outcomes [4-5]. Also a Learning Processes Task Group from the National Mathematics Advisory Panel of the Department of Education [6] concluded that curricula should provide sufficient time on task to ensure acquisition and long term retention of both conceptual and procedural knowledge. While there may be consensus about the value of time-on-task in engineering education finding a solution has proven elusive for a number of reasons. For example, the limited time students spend engaged with formal learning activities. Donovan et al., [7] estimates students spend about $14 \%$ of their day in school. 
Many believe timeline recommendation for engineering education is unrealistic. In reference to reports such as Gathering Storm [8], Engineer of 2020 [9], and How People Learn: Bridging Research and Practice [10], Karen Watson observes that the engineer of 2020 is already in sixth grade, and because universities curricula generally change slowly the recommended goals are unrealistic. "It is going to take course changes, content changes, pedagogical changes, organizational changes, structural changes and cultural changes to realize systems to educate the engineer of 2020" [11]. In addition, the many stakeholders involved in preparing future engineer, and technologists, makes change a complex endeavor given that "technical and non-technical issues are inextricable and increasingly linked" [12]. The complexities of these interconnectivities raise a specter and frustration in process in search of meeting critical competencies recommended in these reports.

\section{PROBLEM-BASED LEARNING (PBL)}

Another important element in preparing students for a global environment is the incorporation of PBL as part of the teaching of technical courses. There are many benefits of using PBL including the development of critical thinking, improving students' analytical abilities, and helping students understand the practical applications of the material presented in class. Universities that adopt PBL move engineering education toward real world challen

ges that are every bit as technical, but also capture the many facets of a successful project or product in the global economy.

\section{COURSE PORTFOLIOS AND LEARNER AGENT OBJECT}

A course portfolio is a document prepared by a student that summarizes each chapter in the course. Preparing a course portfolio forces students to engage in deeper learning, as they have to understand the material thoroughly before they can rewrite it in their own words. A related benefit has to do with improving students' technical writing skills.

Writing skills are essential in any engineering context since the consequences of miscommunication can be expensive. In a globally dispersed supply chain, these consequences can get magnified. Consider a simple example: A sends an email to a supplier, B; B doesn't understand the email; but B is on a different time zone, so B cannot just pick up the phone to clarify the doubt; and so on. Given that a significant amount of engineering disciplinary knowledge cannot be communicated without strong technical writing, having excellent technical writers in the work place is important for seamless collaboration.

A course portfolio also allows instructors to evaluate students' understanding of course material. A helpful way to implement a course portfolio is to let students know that they can use only the course portfolio on the exam, and nothing else. To ensure that students differentiate between important topics and others, students can be asked to limit the length of each chapter portfolio.

Learner Agent Objects (LAO) is not a specific technology or pedagogical methodology instead it is a framework of ideas for creating and transferring knowledge in a digital environment where the capability of the student (learner) transcends biology . LAO aims to use the affordance of digital technology to extend our perception of the individual's capabilities to learn, work and make decision as an informed citizen. This affordance includes continuously accumulating academic artifacts, and simulations, in a permanent personal library for supporting the individual's interaction with stakeholders in the teaching and learning process. Support capabilities are grouped in at least three categories:

1. in artifacts, simulations, and metadata that represent and influence an individual's learning experiences both in and out of the formal engineering education,

2. in exchanging ideas with others,

3 . in analyzing and solving problems. One assumption is that over time and as digital technology matures, the usefulness of this personal library or hub of knowledge would render it an extension of the individual much as a limb or organ in the teaching and learning process. Increase application of market principles in education; philosophy and ethics for digital education enterprises; and heightened interest in understanding how people learn [7]. Students (learners) are generally the only consistently common element in these piecemeal efforts, and for learners to be capable of presenting more complete information about their academic situation to stakeholders in STEM education is the focus of LAO.

LAO raises important philosophical issues about its usefulness in creating knowledge and ethics of a digitally extended student (learner) in a digital environment. For example, issues of control digital property, and compatibility. However, knowledge associated with this academic experience and other important philosophical issues are not the focus of this paper.

In addition, issues of LAO as a smart agent of the individual in a digital environment are also not the focus of this paper, and are best pursued elsewhere using existing agency theory research as a starting point for understanding issues of LAO as a digital agent of the individual learner. This is only a beginning attempt of a first step towards constructing a framework of ideas search for solutions about how to perceive enhanced learning, and enhanced learners, in three broad areas.

1. To prepare future technologists,

2. To prepare future engineers, and

3. To provide a timely delivery system for educating the country's workforce. To demonstrate the proof-ofconcept of LAO in these three categories, Blackboard discussion board was used as a digital container where students continuously accumulate their best work from selected classes.

\section{CONClusion}

This paper problem base learning and student learner agent object portfolio student engagement during the lecture and throughout the semester. Fostering engineering student engagement in the class room is a challenging task that can be met with those two learning strategies. In this paper, the authors proposed the use of Problem-Based Learning (PBL) to maintain student engagement throughout each lecture and the use of course Learner Agent Object (LAO) portfolio to maintain student engagement in the course throughout the semester. 


\section{REFERENCES}

[1] Pieters, Rik, and Baumgartner, Hans. (2002). "Who Talks to Whom? Intra- and Interdisciplinary Communication of Economics Journals". Journal of Economic Literature: 40(2), pp. 483-509.

[2] Alabanese M., \& Mitchell, S. "Problem-based learning: a review of literature on its outcomes and implementation issues," Academic Medicine, Vol. 68, 1993, No. 1.

[3] Baker, D. A., \& Witt, P. A. (1995). Evaluation of the impact of two after-school programs. Journal of Park and Recreation Administration, 14(3), 60-81.

[4] Huang, R. X., M. A. Cane, N. Naik, and P. Goodman (2000), Global adjustment of the thermocline in response to deepwater formation, Geophys. Res. Lett., 27(6), 759-762

[5] Wang, M. C., Haertel, G. D., \& Walberg, H. J. (1993). Toward a knowledge base for school learning. Review of Educational Research, 63(3), 249-294.

[6] Learning Processes Task Group. (2007). National Mathematics Advisory Panel Progress Report. United States Department of Education.

[7] Donovan, Suzanne, John D. Bransford, and James W. Pellegrino, (Eds.). How people learn: bridging research and practice. Committee on Learning Research and Educational Practice,
Commission on Behavioral and Social Sciences and Education, National Research Council.

[8] National Research Council, Rising above the gathering storm: Energizing and employing America for a brighter economic future, Washington, DC: National Academies Press, 2005.

[9] National Academy of Engineering, The engineer of 2020, Washington, DC: National Academies Press. 2004.

[10] National Academy of Engineering, Educating the engineer of 2020: Adapting engineering education to the new century, Washington, DC: National Academies Press, 2005.

[11] Watson, K. "Change in Engineering Education: Where Does Research Fit? Journal of Engineering Education 98 (1): 3-4., 2009 ,

[12] Kurzweil, Ray. (2005) The Singularity is near: when humans transcend biology. Penguin Group. New York, New York.

\section{AUTHORS}

Akram Abu-aisheh, Lynroy Grant, Narendar Sumukadas, and Alan Hadad are with University of Hartford, West Harford, CT, USA.

Submitted 29 July 2016. Published as resubmitted by the authors 13 October 2016. 